\title{
Jurisdição Constitucional brasileira: entre Constitucionalismo e Democracia
}

\author{
Katya Kozicki* \\ Estefânia Maria de Queiroz Barboza**
}

Sumário: 1. Democracia Procedimental; 2. Constitucionalismo; 3. O caso brasileiro. Referências.

\begin{abstract}
Resumo: O presente artigo analisa o papel da Jurisdição Constitucional brasileira a partir das teorias da Democracia Procedimental e do Constitucionalismo. Primeiramente estuda-se a maneira como os teóricos da Democracia Procedimental tratam a possibilidade de atuação da Jurisdição Constitucional na proteção e definição dos direitos fundamentais para a garantia do processo democrático. Em um segundo momento enfoca-se o Constitucionalismo como teoria que prioriza a proteção dos direitos fundamentais, mesmo que isto implique limitação do processo democrático. Por fim demonstra-se que a Constituição brasileira de 1988 adotou uma concepção de democracia substantiva, o que leva à possibilidade da Jurisdição Constitucional limitar os Poderes Executivo e Legislativo visando a proteção dos direitos fundamentais.
\end{abstract}

Palavras-chave: Democracia; Constitucionalismo. Jurisdição constitucional; Direitos fundamentais.
Abstract: This article intends to discuss Brazilian judicial review from the standpoint of deliberative (or procedural) democracy and constitutionalism. It focuses first on the relation between procedural democracy and judicial review stressing the role of the latter in defining and protecting basic rights in order to guarantee the democratic procedure. Second it takes constitutionalism as a theory that emphasizes the protection of basic rights even if it limits the democratic procedure. Then, it shows that the Brazilian Constitution of 1988 has adopted a conception of substantial democracy that leads to the limitation of executive and legislative powers by the judiciary through judicial review in order to protect basic rights.

Keywords: Democracy; Constitutionalism; Judicial review; Basic rights.

O presente artigo pretende trabalhar as concepções de constitucionalismo e de democracia adotadas pela Constituição Federal de 1988, buscando demonstrar que a mesma fundamenta seu caráter democrático nos valores substantivos compartilhados pela sociedade, principalmente por meio dos direitos fundamentais por ela consagrados.

\footnotetext{
* Mestre e doutora em Direito pela UFSC. Visiting Researcher Associate no Center for the Study of Democracy - University of Westminster, Londres, 1998-1999. Professora dos programas de graduação e pós-graduação em Direito da PUCPR e da UFPR.

** Mestre em Direito Econômico e Social pela PUC-PR. Doutoranda em Direito Econômico e Socioambiental pela PUC-PR. Professora de Direito Constitucional da Unibrasil. Advogada em Curitiba.
} 
A primeira idéia que vem à baila quando se fala em democracia é a de governo da maioria. Não obstante, apesar do voto majoritário ser considerado pedra fundamental no sistema da democracia representativa, o mesmo não é suficiente para garantir decisões corretas ou mesmo resultados justos e racionais, uma vez que o princípio majoritário não assegura a igualdade política. Ou seja, o resultado do voto majoritário representa a voz dos vencedores e não necessariamente o bem-comum ou o interesse de todos, e a questão está em saber se apenas o procedimento democrático seria capaz de assegurar um resultado justo e correto para todos. ${ }^{1}$

Por esta razão, nos Estados Constitucionais atuais, o governo da maioria deve conviver com os direitos das minorias, geralmente elevados à categoria de direitos fundamentais, já que o pluralismo e as minorias se fazem presentes, e todos, absolutamente todos, devem ser protegidos.

E é aí que está a tensão entre democracia e constitucionalismo, na medida em que este acaba por limitar a liberdade de deliberação dos representantes eleitos pelo povo que, por sua vez, não podem elaborar leis que afrontem direitos fundamentais das minorias, ou mesmo individuais, elencados na Constituição.

Dessa forma, há aqueles que defendem que o procedimento democrático adequado é suficiente para que se alcance um resultado justo, conforme se verá no primeiro item deste artigo, intitulado "Democracia Procedimental".

Em contraponto a uma concepção procedimental de democracia, no segundo item do presente artigo abordar-se-á o "Constitucionalismo" enquanto "técnica específica de limitação do poder com fins garantísticos"2. Equivale dizer que, para a teoria do Constitucionalismo, é necessário mais do que um procedimento democrático adequado para se alcançar resultados justos, sendo também necessários juízos de valores substantivos, que levem em consideração os resultados a ser alcançados. Os valores substantivos escolhidos pela sociedade são alçados ao status de direitos fundamentais numa Constituição rígida e estes, por sua vez, funcionam como limites materiais à deliberação democrática. Nesta ótica, o Poder Judiciário (ou a Corte Constitucional) é o intérprete final da Constituição, razão por que ela própria lhe assegura competência para controlar os atos emanados do Poder Executivo ou do Poder Legislativo.

Desta forma, o presente artigo buscará explicitar que concepção procedimentalista ou substancialista - predomina na Constituição Federal de 1988.

\footnotetext{
${ }^{1}$ ERIKSEN, Erik Oddvar. Democratic or jurist made law? On the claim to correctness, ARENA Centre for European Studies, University of Oslo, Working Papers WP 04/07, 2004. Disponível em: $<$ www.arena.uio.no/publications/working-papers2004/papers/wp04_7.pdf>. Acesso em: 1 jul. 2005.

${ }^{2}$ CANOTILHO, José Joaquim Gomes. Direito constitucional e teoria da constituição. 3. ed. Coimbra: Almedina, 2000, p. 47.
} 
Ao final, conclui-se que esta, apesar de não excluir a importância do processo democrático, é uma constituição de valores e, por isso, estaria justificada a limitação dos Poderes Executivo e Legislativo pela jurisdição constitucional, bem como o ativismo judicial na definição e proteção dos valores escolhidos pela comunidade.

\section{Democracia Procedimental}

Inicialmente é necessário fazer algumas considerações sobre a chamada "Democracia Procedimental", com o fim específico de analisar de que modo essa concepção de democracia vê a jurisdição constitucional como garantidora dos princípios democráticos, de forma a ajudar na compreensão e quiçá solução da tensão existente entre a jurisdição constitucional e o princípio democrático.

A chamada "democracia procedimental" se funda na defesa do procedimento democrático, na medida em que privilegia os direitos que garantem participação política e processos deliberativos justos ${ }^{3}$, independente do resultado a ser alcançado.

Para a teoria procedimentalista, os valores substantivos de uma sociedade devem ser escolhidos por meio de uma deliberação democrática, ou seja, pelos poderes representativos do povo, quais sejam o Poder Executivo e o Poder Legislativo. De acordo com esta teoria, o Poder Judiciário deve apenas garantir o exercício da democracia, não sendo possível, portanto, a possibilidade do chamado ativismo judicial, visto que a deliberação sobre os valores substantivos de uma sociedade por juízes não eleitos atentaria ao princípio democrático. ${ }^{4}$

A democracia procedimental surge como oposição ao ativismo judicial americano, ou seja, acusa-se o sistema de controle jurisdicional das leis para garantia da Constituição americana de antidemocrático, posto que era inaceitável a "interpretação juridicamente vinculativa, do sentido material de normas constitucionais de conteúdo vago, por um grupo de juízes não-eleitos e irresponsáveis perante os eleitores"s.

\footnotetext{
${ }^{3}$ ERIKSEN, E. O., op.cit., p. 4.

${ }^{4}$ No Brasil, tem-se Marcelo Andrade Cattoni de Oliveira como representante deste pensamento: "Assim, embora a democracia exija uma jurisdição constitucional ofensiva, no sentido da tutela jurídica de direitos constitucionais garantidores de um processo legislativo democrático, essa não deve nem precisa ser uma guardiã republicana de pretensos valores ético-políticos, tidos como homogêneos ou majoritários na sociedade, como, de fato, se comportou a jurisdição constitucional sob o paradigma do Estado Social". OLIVEIRA, Marcelo Andrade Cattoni de. Jurisdição constitucional: poder constituinte permanente? In: SAMPAIO, José Adércio Leite; CRUZ, Álvaro Ricardo de Souza (coord.). Hermenêutica e jurisdição constitucional. Belo Horizonte: Del Rey, 2001, p. 71. E mais à frente: "A tarefa geral da jurisdição constitucional e, especialmente, no controle jurisdicional de constitucionalidade das leis e do processo legislativo, no marco da Constituição da República brasileira, sob paradigma do Estado Democrático de Direito, é a de garantia das condições processuais para o exercício da autonomia pública e da autonomia privada dos co-associados jurídicos, no sentido da interdependência e da equiprimordialidade delas". Ibid., p. 81.
} 
Os defensores desta concepção de democracia vêem o controle de constitucionalidade das leis como antidemocrático, ou seja, a idéia de que um grupo de juízes não eleitos pelo povo não poderia limitar o que foi escolhido pelos representantes do povo, por meio do Parlamento, sob pena de ofensa ao princípio democrático.

John Hart Ely, Habermas e Carlos Santiago Nino ${ }^{6}$ são alguns dos teóricos que defendem uma concepção procedimental de democracia. Estes autores defendem que os valores da sociedade só podem ser definidos num debate democrático realizado pela própria sociedade e não pelo Poder Judiciário, que não teria legitimidade por não ter sido eleito.

Não obstante, os referidos autores admitem o papel da Jurisdição Constitucional enquanto garantidora do procedimento democrático e, portanto, acabam por permitir que a Jurisdição Constitucional venha a proteger os direitos fundamentais que garantem o processo democrático. Ora, ao permitir esta proteção aos direitos fundamentais, os procedimentalistas enfraquecem sua própria teoria, na medida em que admitem julgamentos substantivos por parte da Jurisdição Constitucional tanto na definição de quais direitos fundamentais seriam garantidores do processo democrático, quanto no julgamento e definição dos valores escolhidos e representados por estes direitos fundamentais ${ }^{7}$.

Os procedimentalistas defendem, assim, que os tribunais constitucionais, "ainda que restringindo o princípio majoritário, continuam sendo defensores da soberania popular"s, enquanto garantidores dos direitos fundamentais de participação política e de acesso ao discurso político. Quer dizer, o Judiciário tem legitimidade para restringir a vontade da maioria tão-somente enquanto guardião do procedimento democrático e, por conseguinte, da própria democracia, não lhe cabendo o papel de legislador positivo ou negativo.

Para além disso deve-se ter em vista que "a pretensão teórica de fundar um regime constitucionalista no quadro de uma teoria procedimental do direito pressu-

\footnotetext{
${ }^{5}$ MELLO, Cláudio Ari. Democracia constitucional e direitos fundamentais. Porto Alegre: Livraria do Advogado, 2004, p. 38.

${ }^{6}$ Neste sentido confira-se: HABERMAS, Jürgen. Direito e democracia: entre facticidade e validade. 2. ed. Trad. Flávio Beno Siebeneichler. Rio de Janeiro: Tempo Brasileiro, 2003. 2 v. NINO, Carlos Santiago. The constitution of deliberative democracy. New Haven: Yale University Press, 1996. ELY, John Hart. Democracy and distrust. Fourteenth printing. Cambridge: Harvard University Press, 2002.

${ }^{7}$ BARBOZA, Estefânia Maria de Queiroz. A legitimidade democrática da jurisdição constitucional na efetivação dos direitos fundamentais sociais. Dissertação de Mestrado, PUCPR, Curitiba, 2005.

${ }^{8}$ SOUZA NETO, Cláudio Pereira de. Jurisdição constitucional, democracia e racionalidade prática. Rio de Janeiro: Renovar, 2002, p. 323.
} 
põe que o sistema dos direitos é melhor tutelado pelos próprios órgãos de representação democrática", por meio "dos processos de decisão do regime democrático, do que por cortes de justiça, que não possuem origem e controle popular". ${ }^{10}$

Logo, em que pese a importância das garantias e direitos protegidos segundo a teoria procedimentalista, permitindo a segurança jurídica e a obediência ao princípio da igualdade das partes, tem-se que tais garantias procedimentais não são suficientes para atender nossa sociedade, primordialmente desigual. O princípio da igualdade entre as partes não é suficiente para garantir o direito à igualdade, havendo necessidade de uma discriminação ativa, na busca de uma igualdade material e, portanto, permitindo-se um julgamento de valores por parte do Judiciário, na definição do direito à igualdade no processo democrático.

Enquanto a democracia procedimental se baseia no princípio majoritário como conteúdo importante para o processo democrático, como se este fosse suficiente para garantir igual tratamento aos cidadãos, deve-se ter em vista que a regra majoritária, sob o pretexto de tratar a todos de maneira igual, trata os cidadãos como números e não se preocupa com os motivos ou resultados buscados por estes.

Erik Oddvar Eriksen ${ }^{11}$ entende que o problema com o princípio majoritário, fundamento daqueles que defendem uma democracia baseada no procedimento e não no resultado, é que ele não permite que nenhum interesse ou demanda seja favorecido, nem quando existirem bons motivos para este favorecimento. E conclui que a votação (deliberação) como ato político primário nunca irá representar uma verdadeira igualdade para os grupos minoritários ou excluídos. ${ }^{12}$

Ainda cabe destacar a crítica de L. H. Tribe acerca da teoria procedimentalista, de acordo com o qual as próprias normas que regulam os procedimentos de participação são substantivas:

Decidir que classe de participação demanda a Constituição, requer uma teoria dos valores e dos direitos plenamente substantiva. Assim, os direitos ao procedimento do devido processo têm em sua base a dignidade pessoal (ser ouvido é parte do que significa ser pessoa); do mesmo modo, a questão de 'quem vota' ou a regra 'um homem, um voto' possuem caráter substantivo. As teorias procedimentalistas não parecem apreciar que o processo é algo em si mesmo valioso; porém, dizer que o processo é em si mesmo valioso é afirmar que a Constituição é inevitavelmente substantiva. ${ }^{13}$

\footnotetext{
${ }^{9}$ MELLO, C.A., op.cit., p. 52.

${ }^{10}$ Ibid., ibidem.

${ }^{11}$ Professor da Universidade de Oslo.

${ }^{12}$ ERIKSEN, Erik Oddvar. Democratic or jurist made law?, op. cit.

${ }^{13}$ TRIBE, L. H. The Puzzling Persistence of Process-Based constitutional Theories, apud STRECK, Lenio Luiz. Jurisdição constitucional e hermenêutica: uma nova crítica do direito. 2. ed. Rio de Janeiro: Forense, 2004, p. 161-162.
} 
Dessa forma verifica-se que mesmo os teóricos da democracia procedimental, ao aceitar um papel mínimo de jurisdição constitucional para garantia do próprio processo democrático, não conseguem evitar a possibilidade de que esta jurisdição envolva julgamento de valores substantivos, demonstrando que julgamentos substantivos pelo Poder Judiciário não estão a ofender, de modo algum, o princípio democrático. Isto também porque, ao defender que um processo democrático legítimo e justo é que vai legitimar as leis, os procedimentalistas acabam admitindo algumas pré-condições necessárias a que este procedimento seja o mais adequado, tais como liberdade, igualdade e dignidade dos cidadãos. Isto, por sua vez, demonstra condições necessariamente substantivas.

Feitas estas considerações, como o resultado do discurso procedimental de democracia não depende apenas das qualidades do procedimento democrático para que se garanta um resultado correto e justo, passa-se agora à análise do Constitucionalismo enquanto teoria construída sobre concepções substantivas de justiça e que, por sua vez, dá maior prioridade aos resultados justos do que aos procedimentos democráticos.

\section{Constitucionalismo}

Diversamente da "Democracia Procedimental", que prioriza o processo democrático independentemente dos resultados a ser obtidos, o Constitucionalismo é a teoria que, baseada numa Constituição rígida, busca resultados que venham a garantir a proteção dos direitos fundamentais, mesmo que isso importe limitação dos poderes do Executivo e do Legislativo.

O Constitucionalismo tem como pedra angular os direitos fundamentais que, por sua vez, representam os valores substantivos escolhidos pela sociedade no momento constituinte, de máxima manifestação da soberania popular. São estes direitos que garantem o funcionamento da democracia, isto é, quando os direitos fundamentais impõem limites materiais aos atos do governo estão, na verdade, protegendo o povo como um todo e não apenas maiorias eventuais. E quem está incumbido de proteger estes valores é o Poder Judiciário ${ }^{14}$, conforme determinação do próprio Poder Constituinte.

A idéia de substantividade ou de materialidade das Constituições deriva tanto de uma oposição ao procedimentalismo ou a uma concepção procedimental de democracia que vêem a Constituição enquanto garantia procedimental da democra-

\footnotetext{
${ }^{14}$ No Sistema Constitucional europeu foram criados Tribunais ou Cortes Constitucionais independentes do Poder Judiciário.
} 
cia, como de uma idéia de proteção de valores substantivos por meio dos direitos fundamentais ${ }^{15}$.

A doutrina brasileira, como a européia do pós-guerra, foi influenciada por teóricos da teoria substantiva norte-americana ${ }^{16}$, em que impera o judicial review, o qual permite um controle substantivo da Constituição por parte do Poder Judiciário, de modo a rever as leis emanadas pelo Legislativo e incompatíveis com os valores substantivos da Constituição.

A polêmica que gira em torno do judicial review consiste basicamente no seu suposto caráter antidemocrático, na medida em que permite que juízes não eleitos pelo povo possam interpretar os valores substantivos presentes na Constituição, como também revisar e anular leis incompatíveis com tais valores, mesmo que provenientes do Parlamento, enquanto representante democrático do povo, numa tensão entre jurisdição constitucional e democracia.

Eugene Rostow, rebatendo os argumentos contrários ao judicial review pelos teóricos procedimentalistas, os quais defendem que os valores substantivos da Constituição podem ser interpretados e modificados apenas pelos poderes eleitos democraticamente pelo povo, afirma que "é uma grande simplificação sustentar que uma sociedade não pode ser democrática a menos que os seus parlamentos tenham poderes soberanos". ${ }^{17}$

Se a finalidade de uma sociedade "é garantir o máximo de liberdade possível para os seres humanos" 18 , o objetivo final de uma Constituição deve ser o de "assegurar às pessoas uma sociedade livre e democrática"19. Desse modo, a Constituição aparelha a sociedade com um governo para atingir esses objetivos. No entanto, não se pode conceber que este governo tenha poderes irrestritos. Os direitos fundamentais de liberdade atuam como limites ao poder do governo e o papel da jurisdição constitucional é justamente o de proteger esses direitos, ainda que seja contra atos do próprio governo. Não há aí qualquer caráter antidemocrático,

\footnotetext{
${ }^{15}$ MELLO, C. A., op. cit., p. 85.

${ }^{16}$ Veja-se que, apesar da rejeição do modelo de justiça constitucional com controle difuso de constitucionalidade pelo sistema europeu, caracterizado pelo receio do governo de juízes, relegando às Cortes Constitucionais o papel do judicial review, a proteção dos direitos fundamentais nas Constituições Democráticas, surgidas na metade do século XX, tem evidente influência do modelo norte-americano do Bill of Rights. Ver nesse sentido: FAVOREU, Louis. As cortes constitucionais. Trad. Dunia Marinho Silva. São Paulo: Landy, 2004, p. 18-22; e CAPPELLETTI, Mauro. O controle judicial de constitucionalidade das leis no direito comparado. 2. ed. Porto Alegre: Sérgio Antonio Fabris, 1999, p. 46 et. seq.

${ }^{17}$ MELLO, C.A., op. cit., p. 86.

${ }^{18}$ Ibid., ibidem.

${ }^{19}$ ROSTOW, Eugene. The democratic character of judicial review. Harvard Law Review 66 (1952) apud MELLO, C.A., op. cit., p. 86.
} 
visto que os direitos de liberdade acabam também por assegurar o processo democrático.

Para Ronald Dworkin é equivocada a idéia de que deixar o Tribunal decidir sobre uma questão polêmica é antidemocrático, e que esta decisão deveria ser decidida por um processo democrático. Ele exemplifica com o aborto, que deve ser decidido pelo poder jurisdicional uma vez que, caso fosse submetido à maioria, justificar-se-á referida lei com base em opiniões morais. Dworkin quer, precisamente, evitar este tipo de decisão majoritária, por entender que a mesma pode ofender sua teoria de igualdade de representação. ${ }^{20}$

Dworkin também rebate o juízo segundo o qual a Suprema Corte não deve substituir julgamentos legislativos substantivos por novos julgamentos de sua autoria, bem como a idéia de que o nível certo do controle de constitucionalidade seria buscar a intenção dos constituintes ${ }^{21}$, como defendem os originalistas, devendo o Tribunal atuar apenas policiando os processos da própria democracia. Até porque essas teorias se auto-anulam, posto que, ao tentar evitar julgamentos judiciais substantivos, incorporam os julgamentos substantivos que justamente dizem ser de competência do povo. ${ }^{22}$

\footnotetext{
${ }^{20}$ DWORKIN, Ronald. Uma questão de princípio. São Paulo: Martins Fontes, 2000, p. 100.

21 “A primeira estratégia alternativa, como já disse, aceita a leitura moral. A segunda, chamada de 'originalista' ou 'intenção original' não aceita. A leitura moral insiste em que a Constituição significa o que os constituintes queriam dizer. $\mathrm{O}$ 'Originalismo' insiste que ele significa o que eles esperavam que o modo de escrever deles realizasse, e como já disse, é um outro assunto. (Apesar de alguns 'originalistas, incluindo um dos mais conservadores juízes, agora na Corte Suprema, Antonin Scalia, não serem claros com relação à distinção.) De acordo com o 'Originalismo', os principais artigos do Bill of Rights deveriam ser interpretados não como impondo princípios morais abstratos, como eles descrevem, mas ao contrário, referindo-se, em forma de código ou disfarce, às suposições e expectativas dos próprios constituintes sobre a aplicação daqueles princípios. Portanto o artigo de igualdade de proteção deve ser entendido como comandando não igualdade de condições, mas o que os próprios constituintes pensavam ser igualdade de condições, apesar do fato de que, como eu disse, os constituintes claramente queriam impor o modelo anterior e não o mais atual. A decisão de Brown que acabo de mencionar clara e objetivamente demonstra a distinção. A decisão da Corte foi claramente requisitada sob o ponto de vista de uma leitura moral, porque agora é óbvio que a segregação oficial em escolas não é consistente com igualdade de condições e respeito a todas as raças. Mas a estratégia 'originalista', consistentemente usada, teria demandado a conclusão oposta, porque, como já disse, os autores do artigo de proteção de igualdade não acreditavam que segregação na escola, que eles próprios praticavam, era uma negação de igualdade de condições, e não esperavam que um dia poderia imaginar ser. A leitura moral insiste em que eles entenderam mal o princípio moral o qual ele próprios estabeleceram como lei. A estratégia 'originalista' traduziria um equívoco em uma duradoura lei constitucional". DWORKIN, Ronald. Freedom's law: the moral reading of the American Constitution, Second Printing. Cambridge: Harvard University Press, 1996, p. 13. Todas as traduções de notas e comentários presentes neste artigo são traduções livres realizadas pelas autoras com fins exclusivamente acadêmicos.
}

${ }^{22}$ DWORKIN, Ronald, Uma questão de princípio, op.cit., p. 101. 
Por conseguinte, sustenta Dworkin que:

(...) o Tribunal deve tomar decisões de princípio, não de política - decisões sobre que direitos as pessoas têm sob nosso sistema constitucional, não decisões sobre como se promove melhor o bem-estar geral-, e que deve tomar essas decisões elaborando e aplicando a teoria substantiva da representação, extraída do princípio básico de que o governo deve tratar as pessoas como iguais. ${ }^{23}$

Dessa forma defende o autor que o judicial review deve procurar garantir direitos por intermédio de decisões de princípios e não de política. ${ }^{24}$

Verifica-se, assim, que não foi só Dworkin que defendeu uma teoria de legitimidade das decisões judiciais baseadas em princípios. Entretanto, a diferença de sua teoria consiste no fato de ser a mesma substantiva, ou seja, para ele os princípios atuam enquanto exigência de justiça e de eqüidade, correspondendo a um valor moral substantivo. ${ }^{25}$

Dworkin admite, com isso, a possibilidade de legitimidade dos julgamentos constitucionais pelo Poder Judiciário, desde que baseados em princípios, entendidos como um padrão a ser observado em face da "exigência de justiça ou eqüidade ou alguma outra dimensão de moralidade". ${ }^{26}$

A substantividade está presente nos princípios, os quais indicam valores de moralidade e de justiça, ou seja, "a leitura moral da Constituição supõe, em primeiro lugar, que os direitos fundamentais nela estabelecidos devem ser interpretados como princípios morais que decorrem da justiça e da eqüidade"27 e que, por sua vez, levam à fixação de limites ao poder governante.

Por outro lado, Dworkin não aceita como legítimas as decisões judiciais baseadas em argumentos de política (policy), entendendo como política "aquele tipo de padrão que estabelece um objetivo a ser alcançado, em geral uma melhoria em algum aspecto econômico, político ou social da comunidade"28. Assim, os julgamen-

\footnotetext{
${ }^{23}$ Ibid, ibidem.

${ }^{24}$ Não obstante, como Dworkin coloca os juízes sujeitos à doutrina da responsabilidade política e, por conseqüência, às decisões por eles emanadas, "também as decisões judiciais podem ser consideradas decisões políticas". Katya. Conflito e estabilização: comprometendo radicalmente a aplicação do direito com a democracia nas sociedades sontemporâneas. Tese de Doutorado, Universidade Federal de Santa Catarina, Florianópolis, 2000, p. 185.

${ }^{25}$ MELLO, C.A., op. cit., p. 90.

${ }^{26}$ DWORKIN, Ronald. Levando os direitos a sério, Trad. Nelson Boeira. São Paulo: Martins Fontes, 2002, p. 36.

${ }^{27}$ CITTADINO, Gisele. Pluralismo, direito e justiça distributiva: elementos da filosofia constitucional contemporânea. 3. ed. Rio de Janeiro: Lúmen Júris, 2004, p. 191.

${ }^{28}$ DWORKIN, R. Levando os direitos a sério, p. 36.
} 
tos de política são de atribuição exclusiva dos Poderes Legislativo e Executivo (democraticamente eleitos pelo povo) e, conseqüentemente, não podem ser objeto de controle ou aplicação pelos tribunais..$^{29}$ Desse modo, Dworkin consegue balancear o princípio democrático com o princípio constitucional.

Dworkin, inclusive, defende a supremacia da Constituição em sentido material, uma vez que os princípios constitucionais podem ser também princípios morais, que uma Constituição verte em jurídicos ${ }^{30}$.

Cláudio Pereira de Souza Neto explica bem a questão da legitimação da jurisdição constitucional conforme a teoria de Dworkin:

No tocante à jurisdição constitucional, Dworkin irá legitimá-la da seguinte maneira. Se, em um caso difícil, o magistrado, não podendo aplicar uma regra, aplica um princípio, não está criando direito novo, mas aplicando o direito preexistente. Por conta disso, a inclusão dos princípios no sistema jurídico resolve os problemas de legitimação dos tribunais constitucionais criados pela concepção volitiva da jurisdição presente no modelo normativista. É essencial destacar, no entanto, que somente os argumentos de princípio podem justificar a jurisdição constitucional. $\mathrm{O}$ autor não concebe a possibilidade de que um argumento político, utilizado pelo poder judiciário, possa anular normas cuja produção no âmbito do legislativo também se fundam em argumentos políticos. ${ }^{31}$

Dessa forma, conclui Souza Neto que a justificação teórica de Dworkin acaba por não se afastar, no que diz respeito à separação de poderes, da proposta liberal-positivista, com a diferença de que, para Dworkin, os princípios são reconhecidos como direito ${ }^{32}$.

Ainda é de se ter em conta a posição de Dworkin contra a teoria majoritária de democracia, por entender que esta não pode ser o único fundamento da democracia. Ele sustenta que a proteção dos direitos por via jurisdicional acabaria por fortalecer o próprio processo democrático, bem como o princípio da igual consideração e respeito. Este princípio é considerado por ele o fundamento básico de uma democracia constitucional, que acaba sendo mais bem respeitado por tribunais que podem controlar os atos de outros poderes, do que em sistemas nos quais os Poderes Legislativo e Executivo exercem soberania total, sem nenhum tipo de limitação.

\footnotetext{
${ }^{29}$ MELLO, C. A., op. cit., p. 90.

${ }^{30}$ SOUZA NETO, C. P. Jurisdição constitucional, democracia e racionalidade prática, op.cit., p. 246.

${ }^{31}$ Ibid., p. 247.

${ }^{32}$ Ibid., p. 247.
} 
Além disso, Dworkin defende a supremacia dos direitos fundamentais, os quais, segundo ele, dariam legitimidade suficiente à atuação do Poder Judiciário na revisão das leis editadas pelo Parlamento ou atos emanados pelo Executivo, quando as referidas leis estiverem em contrariedade àqueles direitos fundamentais.

Não se pode descurar, ainda, que para Dworkin um dos papéis primordiais da Constituição seria não somente a proteção dos indivíduos, mas também dos grupos minoritários, contra decisões da maioria, mesmo que esta maioria esteja convencida de que sua decisão estará promovendo o bem-estar geral ${ }^{33}$, ou seja:

A teoria constitucional em que se baseia nosso governo não é uma simples teoria da supremacia das maiorias. A Constituição, e particularmente a Bill of Rights (Declaração de Direitos e Garantias), destina-se a proteger os cidadãos (ou grupos de cidadãos) contra certas decisões que a maioria pode querer tomar, mesmo quando essa maioria age visando o que considera ser o interesse geral ou comum. ${ }^{34}$

Por conseguinte, Dworkin consegue fundamentar o ativismo judicial, possibilitando a revisão judicial das leis editadas pelo Parlamento por juízes, que julgarão com base em princípios substantivos. Ou seja, para Dworkin, "cabe ao magistrado se orientar pela moralidade social cambiante, promovendo interminavelmente a reconstrução do ordenamento jurídico vigente com base nos princípios contemporâneos da moralidade política". ${ }^{35}$ Em suas palavras:

Nosso sistema constitucional baseia-se em uma teoria moral específica, a saber, a de que os homens têm direitos morais contra o Estado. As cláusulas difíceis da Bill of Rights, como as cláusulas do processo legal justo e da igual proteção, devem ser entendidas como um apelo a conceitos morais, e não como uma formulação de concepções específicas. Portanto, um tribunal que assume o ônus de aplicar plenamente tais cláusulas como lei deve ser um tribunal ativista, no sentido de que ele deve estar preparado para formular questões de moralidade política e dar-lhes uma resposta. ${ }^{36}$

Dworkin sustenta, dessa maneira, que a tutela dos direitos fundamentais está na essência do constitucionalismo, o que acaba por demonstrar que o judicial review pode conviver em total harmonia com o princípio da democracia tendo em vista que os juízes, "ao adotarem a leitura moral da constituição" 37 , nada mais estão fazendo

\footnotetext{
${ }^{33}$ MELLO, C. A., op.cit., p. 91-92.

${ }^{34}$ DWORKIN, R. Levando os direitos..., op. cit., p. 208-209.

${ }^{35}$ SOUZA NETO, C. P., Jurisdição..., op. cit., p. 248.

${ }^{36}$ DWORKIN, R., Levando os direitos..., op.cit., p. 231.

${ }^{37}$ MELLO, C. A., op. cit., p. 93.
} 
do que adotando valores políticos e morais escolhidos pelo próprio povo quando do processo constituinte, representação máxima e soberana da vontade do povo ${ }^{38}$.

Contrário a uma concepção majoritária de democracia, Dworkin defende uma concepção constitucional de democracia, ou seja, um regime de governo no qual as decisões coletivas são tomadas por instituições políticas cuja estrutura, composição e práticas tratem a todos os membros de uma comunidade com igual consideração e respeito. Em suas palavras:

Se rejeitarmos a premissa majoritária, necessitaremos de um conjunto diferente e melhor de valor e de importância da democracia. Mais tarde defenderei um ponto - que eu chamo de concepção constitucional de democracia - que, sim, rejeita a premissa majoritária. Ela nega que é um objetivo que define a democracia que decisões coletivas sempre - ou normalmente - são aquelas em que a maioria ou muitos cidadãos estariam a favor de modo completamente informados e racionais. Ela precisa do objetivo definido de democracia para ser uma concepção diferente: que as decisões coletivas sejam tomadas por instituições políticas, cuja estrutura, composição e prática tratem todos os membros de uma comunidade, como indivíduos com igual consideração e respeito. Essa consideração alternativa a respeito do objetivo da democracia, é verdade, exige tanto da estrutura governamental como a exige a premissa majoritária. Demanda que as decisões políticas do dia-a-dia sejam tomadas por autoridades que tenham sido eleitas diretamente pelo povo. Mas a concepção constitucional de democracia exige que esses métodos majoritários não estejam preocupados com a questão da igualdade de condições dos cidadãos, o que não significa que estejam fora do compromisso dos objetivos de uma regra majoritária. Então, ela não oferece nenhuma razão pela qual alguns procedimentos majoritários deveriam ser aplicados em ocasiões especiais quando protegeria melhor ou melhoraria a igualdade de condições que mostra ser a essência da democracia e não aceita que essas exceções sejam a razão para uma rejeição moral. ${ }^{39}$

A concepção constitucional de democracia prevê que as decisões de política sejam tomadas por agentes eleitos democraticamente pelo povo. Não obstante, permite que o Judiciário, mesmo tendo caráter contramajoritário, possa tomar decisões sobre direitos, já que em alguns casos os tribunais estão mais preparados para proteger direitos que garantem igual consideração e respeito, ou que "os legisladores não estão, institucionalmente, em melhor posição que os juízes para

\footnotetext{
${ }^{38}$ Ibid, ibidem.

${ }^{39}$ DWORKIN, Ronald, Freedom's law..., op. cit., p. 17.
} 
decidir questões sobre direitos" ${ }^{\text {"40 }}$. Até porque nestes casos os juízes têm maiores condições de ser imparciais do que os representantes eleitos ${ }^{41}$, posto que os legisladores podem estar sujeitos a pressões a que não estão sujeitos os juízes. ${ }^{42} \mathrm{E}$ conclui que não há nenhuma razão para pensar que "a transferência de decisões sobre direitos, das legislaturas para os tribunais, retardará o ideal democrático da igualdade de poder político" 43 , mas, ao contrário, "pode muito bem promover esse ideal" $" 4$.

Apesar disso, esta transferência de decisões sobre direitos para os tribunais não implica que estes possam tomar decisões políticas, uma vez que, para Dworkin, mesmo nos casos difíceis vão existir princípios a ser aplicados pelos juízes, não havendo, conseqüentemente, uma mera discricionariedade.

A concepção substantiva admite, assim, que a Constituição possui valores que devem ser respeitados não só pelos cidadãos, mas também pelos Poderes Executivo, Legislativo e Judiciário, cabendo a este a fiscalização dos demais Poderes, em razão de sua conformidade aos direitos fundamentais e aos princípios constitucionais previstos na Constituição. Neste sentido não se deve falar em mera adequação procedimental dos processos políticos, mas em verdadeira adequação material.

Segundo a teoria substantiva da Constituição, ou constitucionalista da democracia, existem direitos fundamentais que representam valores mínimos escolhidos pelo povo no momento constituinte que devem ser protegidos inclusive contra maiorias eventuais. A Constituição, desse modo, se dirige a todos os cidadãos e a todos os Poderes do Estado, mas seu protetor e intérprete máximo, neste modelo, é o Poder Judiciário ${ }^{45}$, que, por sua vez, irá interpretar os valores escolhidos pela sociedade quando da elaboração da Constituição permitindo dessa forma uma idéia de ativismo judicial na proteção e efetivação dos direitos fundamentais.

Passa-se agora a enfrentar qual concepção de democracia foi adotada pela Constituição Federal de 1988 e qual papel deve ser assumido pela Jurisdição Constitucional brasileira.

\footnotetext{
${ }^{40}$ Idem. Uma questão de princípio, p. 27.

${ }^{41}$ MELLO, C. A, op.cit., p. 93.

${ }^{42}$ DWORKIN, R., Uma questão de princípio, p. 27.

${ }^{43}$ Ibid., p. 32.

${ }^{44}$ Ibid., ibidem.

${ }^{45} \mathrm{Ou}$ Tribunal Constitucional nos países europeus que criaram um Tribunal ou Corte independente do Poder Judiciário.
} 


\section{O Caso Brasileiro}

No Brasil, a maioria dos autores defende uma Constituição de valores - entre estes estão Luis Roberto Barroso ${ }^{46}$, Clèmerson Merlin Clève ${ }^{47}$, Lenio Luiz Streck, Ingo Wolfgang Sarlet, Gilberto Bercovici, Giselle Cittadino, Paulo Bonavides e Ana Paula de Barcellos.

Por questões puramente acadêmicas abordar-se-á neste artigo apenas as posições de Lenio Luiz Streck, Giselle Cittadino e Luís Fernando Barzotto. Estes autores aparentemente têm posições diferentes, mas ao final todos afirmam a substantividade da Constituição brasileira, a supremacia dos direitos fundamentais e a necessidade de um certo ativismo judicial para concretização dos direitos fundamentais constitucionais.

Lenio Luiz Streck parte da premissa de que a Constituição Federal de 1988 criou um novo paradigma ao estabelecer que a República Federativa do Brasil constituiu-se em Estado Democrático de Direito, dando um novo papel ao Poder Judiciário e à Justiça Constitucional, que seriam guardiões dos valores materiais positivados na Constituição. ${ }^{48}$

Para Streck, à noção de Estado Democrático de Direito se acopla "o conteúdo material das constituições, por meio dos valores substantivos que apontam para uma mudança do status quo da sociedade". ${ }^{49}$

Streck explica a evolução histórica que gera esses novos valores constitucionais a ser protegidos pela jurisdição constitucional, deslocando a tensão existente sobre o Poder Executivo no Estado Social para o Poder Judiciário no Estado Democrático de Direito:

A democratização social, fruto das políticas do Welfare State, o advento da democracia no segundo pós-guerra e a redemocratização de países que saíram de regi-

\footnotetext{
46 BARROSO, Luís Roberto. O direito constitucional e a efetividade de suas normas: limites e possibilidades da Constituição brasileira, 7. ed., Rio de Janeiro, Renovar, 2003.

47 “Clèmerson, após destacar que a Constituição de 1988 reclama um judiciário vinculado às diretivas e às diretrizes materiais da Constituição, um judiciário ativista, voltado para a plena realização dos comandos constitucionais e para compensar as desigualdades e o descuido da sociedade brasileira para com a dignidade da pessoa humana, diz que disso não resultaria o judiciário 'atuar como legislador, nem que deve se substituir à atividade do administrador, mas sim que a Constituição Federal exige um novo tipo de juiz, não apenas apegado aos esquemas da racionalidade formal e, por isso, muitas vezes, simples guardião do status quo"'. AMARAL, Gustavo. Direito, escassez \& escolha: em busca de critérios jurídicos para lidar com a escassez de recursos e as decisões trágicas, Rio de Janeiro: Renovar, 2001, p. 17.

${ }^{48}$ STRECK, L. L, op. cit., p. 147.

${ }^{49}$ Ibid., p. 148.
} 
mes autoritários/ditatoriais, trazem à luz Constituições cujos textos positivam os direitos fundamentais e sociais. Esse conjunto de fatores redefine a relação entre os Poderes do Estado, passando o Judiciário (ou os tribunais constitucionais) a fazer parte da arena política, isto porque o Welfare State lhe facultou o acesso à administração do futuro, e o constitucionalismo moderno, a partir da experiência negativa de legitimação do nazi-fascismo pela vontade da maioria, confiou à justiça constitucional a guarda da vontade geral, encerrada de modo permanente nos princípios fundamentais positivados na ordem jurídica. Tais fatores provocam um redimensionamento na clássica relação entre os Poderes do Estado, surgindo o Judiciário (e suas variantes de justiça constitucional, nos países que adotaram a fórmula dos tribunais $a d h o c$ ) como uma alternativa para o resgate das promessas da modernidade, onde o acesso à justiça assume um papel de fundamental importância, através do deslocamento da esfera de tensão, até então calcada nos procedimentos políticos, para os procedimentos judiciais. ${ }^{50}$

Ao analisar as teorias procedimentalistas e substantivas, Lenio Streck faz uma aprofundada crítica às teorias procedimentalistas, por entender que a própria concepção procedimental "não pode prescindir de juízos de substância", visto que "as inadequações das leis só podem ser resolvidas pela tarefa criativa dos juízes". ${ }^{51}$

Para Streck, a teoria procedimentalista de Habermas, por exemplo, não pode ser aplicada no Brasil, já que a teoria do discurso pressupõe cidadãos autônomos e instruídos, o que não ocorre em nosso país.

Dessa forma levanta Streck as seguintes questões:

Como ter cidadãos plenamente autônomos, como Habermas propugna, se o problema da exclusão social não foi resolvido? Como ter cidadãos plenamente autônomos se suas relações estão colonizadas pela tradição que lhes conforma o mundo da vida? Nesse sentido, com Ackerman, há que se perguntar: Pode uma eleição ser livre e justa, se uma grande parte do eleitorado carece de instrução necessária para compreender as principais linhas do debate político? Ou se estão passando fome ou trabalhando em condições opressivas durante a maior parte de seu tempo? 'Minha resposta é não', vai dizer Ackerman. ${ }^{52}$

Assim, não obstante aceitar que os procedimentos democráticos constituem uma parte importante do regime democrático, entende Streck que isto não é suficiente, eis que "não pode existir nenhuma sociedade sem uma definição, mais ou menos segura, de valores substantivos partilháveis, de bens sociais comuns". ${ }^{53}$

\footnotetext{
${ }^{50}$ Ibid., ibidem.

${ }^{51}$ Ibid., p. 152.

${ }^{52}$ Ibid., p. 174.

${ }^{53}$ Ibid., p. 153.
} 
Desse modo adere o autor à corrente substantiva, defendendo um novo papel ao Poder Judiciário, entendido como justiça constitucional e atuando de modo a levar em conta "a perspectiva de que os valores constitucionais têm precedência mesmo contra textos legislativos produzidos por maiorias eventuais" 54 , sendo a Constituição não apenas um instrumento da soberania democrática definidora de procedimentos para elaboração e aplicação das leis, mas também a organização e qualificação destes procedimentos ordinários, de modo que não haja "usurpação da soberania popular por parte de instituições públicas ou privadas"

Para ele, a dimensão material da democracia substantiva estaria calcada nos princípios e direitos fundamentais estabelecidos pela Constituição, ou seja, a Constituição acaba por estabelecer os limites do que deve e do que não pode ser decidido por qualquer maioria, obrigando deste modo "a legislação, sob pena de invalidade, a respeitar os direitos fundamentais e os demais princípios axiológicos por ela estabelecidos" $" 56$.

Por fim, propõe Streck uma "resistência constitucional", para a qual o novo modelo constitucional deve superar o esquema da igualdade formal rumo à igualdade material, assumindo, assim,

(...) uma posição de defesa e suporte da constituição como fundamento do ordenamento jurídico e expressão de uma ordem de convivência assentada em conteúdos materiais de vida e em um projeto de superação da realidade alcançável com a integração das novas necessidades e a resolução dos conflitos alinhados com os princípios e critérios de compensação constitucionais. ${ }^{57}$

Verifica-se, portanto, que Streck é contrário ao modelo procedimentalista, na medida em que defende um maximalismo constitucional, não só no sentido de ativismo judicial, mas no de uma postura realmente intervencionista pelo Poder Judiciário, que deve buscar uma igualdade material de forma a proteger concretamente os direitos fundamentais que não foram realizados pelos demais Poderes.

Outra grande contribuição à corrente substantiva foi dada por Giselle Cittadino. Esta autora, ainda que se intitule adepta do chamado "constitucionalismo comunitário", defende uma concepção substantiva de Constituição, uma vez que compartilha "com a jurisprudência de valores alemã e com o comunitarismo norte-americano a idéia fundamental de que a Constituição traduz uma 'ordem concreta de valores' compartilhada pela comunidade" 58 e que, "através dos mais diversos mecanismos

\footnotetext{
${ }^{54}$ Ibid., p. 180.

${ }^{55}$ Ibid., ibidem.

${ }^{56}$ Ibid., p. 182.

${ }^{57}$ Ibid., p. 192-193.

${ }^{58}$ CITTADINO, Gisele. Pluralismo, direito e justiça distributiva, op. cit., p. 227.
} 
de participação político-jurídica, deve buscar realizá-la, concretizando, assim, o seu direito a autodeterminação" 59 .

Apesar de propugnar uma maior participação da comunidade de intérpretes da Constituição, Cittadino prioriza a supremacia dos direitos fundamentais e defende que a Constituição Federal de 1988 é substantiva e que seu intérprete maior é o Judiciário.

Para Cittadino, a Constituição Federal de 1988 inovou por assumir seu papel de Constituição dirigente, ao definir fins e programas de ação futura ${ }^{60}$, conforme explicação de José Afonso da Silva:

O Constituinte fez uma opção muito clara por uma Constituição abrangente. Rejeitou a chamada constituição sintética, que é constituição negativa, porque construtora apenas de liberdade-negativa ou liberdade-impedimento, oposta à autoridade, modelo de constituição que, às vezes, se chama de constituição-garantia (ou constituição-quadro). A função garantia não só foi preservada como até ampliada na Constituição, não como mera garantia do existente ou como simples garantia das liberdades negativas ou liberdades-limite. Assumiu ela a característica de constituição-dirigente, enquanto define fins e programa de ação futura, menos no sentido socialista do que no de uma orientação social, democrática, imperfeita, reconheça-se. Por isso, não raro, foi minuciosa, e, no seu compromisso com a garantia das conquistas liberais e com um plano de evolução política de conteúdo social, nem sempre mantém uma linha de coerência doutrinária firme. Abre-se, porém, para transformações futuras, tanto seja cumprida. E aí está o drama de toda constituição dinâmica: ser cumprida. ${ }^{61}$

Para a autora, a estrutura normativa da Constituição envolve um conjunto de valores e a Constituição tem, portanto, como objetivo principal, "a realização dos valores que apontam para o existir da comunidade" ${ }^{\prime 62}$, em oposição à concepção liberal de Constituição que vê como tarefa primeira da Constituição a defesa da autonomia dos indivíduos.

Além disso, Cittadino também defende a idéia de constituição aberta, em oposição ao sistema fechado de garantias da autonomia privada, enfatizando, desse modo, os valores socioculturais da comunidade ${ }^{63}$. Ou seja, enquanto um sistema aberto, o Estado democrático de direito brasileiro "tem uma estrutura dialógica,

\footnotetext{
${ }^{59}$ Ibid., ibidem.

${ }^{60}$ Ibid., p. 15.

${ }^{61}$ SILVA, José Afonso da. Curso de direito constitucional positivo, 13. ed., São Paulo: Malheiros, 1997 , p. 8.

${ }^{62}$ CITTADINO, G., op. cit., p. 16.

${ }^{63}$ Ibid., ibidem.
} 
traduzida na disponibilidade e 'capacidade de aprendizagem' das normas constitucionais para captarem a mudança da realidade e estarem abertas às concepções cambiantes da 'verdade' e da 'justiça"'64.

Além disso, a autora defende que os direitos fundamentais do homem funcionam como "restrição imposta pela soberania popular aos poderes constituídos do Estado que dela dependem" ${ }^{65}$. Por conseguinte, Cittadino vê os direitos fundamentais como valores reconhecidos pela comunidade e que devem, pois, ingressar no texto constitucional. Ademais, a partir do momento em que assumem o caráter concreto de normas constitucionais positivas, devem ser considerados direitos constitucionais.

Decorre daí que, enquanto valor constitucional, o sistema de direitos fundamentais se caracteriza como o núcleo básico de todo o ordenamento constitucional, ao mesmo tempo em que lhe serve como base de interpretação. E, porque são direitos positivados, os direitos fundamentais são metas e objetivos a ser alcançados pelo Estado Democrático de Direito. ${ }^{66}$

Cittadino defende que a Constituição brasileira tem várias "marcas" que demonstram sua preocupação não só com o procedimento democrático, mas principalmente com os objetivos e resultados a ser alcançados por meio dele, e adotando valores substantivos escolhidos pela comunidade, quais sejam: i) no preâmbulo, a identificação da igualdade e justiça como valores supremos da sociedade brasileira; ii) a definição dos objetivos e fundamentos do Estado Brasileiro (art. $3^{\circ}$ ), "destacando a dignidade da pessoa humana e a construção de uma sociedade justa e solidária"; iii) adoção de uma "sociedade aberta de intérpretes da Constituição", na medida em que prevê diversos institutos processuais que alargam o círculo de intérpretes da Constituição; iv) concessão ao Supremo Tribunal Federal de atribuições jurídicopolíticas de uma verdadeira Corte Constitucional. ${ }^{67}$

Assim, Cittadino propugna que a Constituição é uma ordem concreta de valores que deve ser realizada não só pelos Poderes Executivo e Legislativo, mas também pelo Judiciário que, por sua vez, deve desempenhar papel político relevante no sistema constitucional, podendo inclusive sobrepor-se ao Legislativo ${ }^{68}$.

Cittadino defende, ainda, uma maior participação dos cidadãos no processo de concretização dos valores constitucionais, ampliando-se a comunidade de intérpretes da Constituição, assim como proposto por Peter Häberle ${ }^{69}$, permitindo-se que

${ }^{64}$ CANOTILHO, J. J. G., op. cit., p. 1085.

${ }^{65}$ CITTADINO, G., op. cit., p. 17.

${ }^{66}$ Ibid., p. 18.

${ }^{67}$ Ibid., p. 228.

${ }^{68}$ Ibid., p. 64.

${ }^{69} \mathrm{Cf}$. HÄBERLE, Peter. Hermenêutica constitucional. A sociedade aberta dos intérpretes da constituição: contribuição para a interpretação pluralista e "procedimental" da Constituição. Trad. Gilmar Ferreira Mendes. Porto Alegre: Sérgio Antonio Fabris, 2002. 
cidadãos, partidos políticos e associações integrem o círculo de intérpretes da Constituição e, conseqüentemente, democratizando o próprio processo interpretativo da Constituição. ${ }^{70}$

A este respeito, Cittadino coloca:

Com a definição do caráter político do Supremo Tribunal Federal, fecha-se o círculo que caracteriza a dimensão comunitária do ordenamento constitucional brasileiro. A realização dos valores constitucionais e a efetivação do sistema de direitos fundamentais vai depender, por um lado, da participação jurídico-política de uma ampla comunidade de intérpretes, dotada de instrumentos processuais inibidores das omissões do poder público, e, por outro, de uma hermenêutica constitucional que, ultrapassando o formalismo positivista, introduza uma consideração de ordem axiológica na tarefa de interpretação da Constituição. ${ }^{71}$

Por outro lado, Cittadino defende o papel político do Supremo Tribunal Federal, não se tratando o mesmo de órgão neutro e, portanto, sustenta que deve buscar procedimentos interpretativos de legitimação de aspirações sociais, à luz da Carta Constitucional de $1988^{72}$. Ou seja, se a Constituição é um sistema de valores, "a sua tutela, por via interpretativa, não pode senão se transformar em instrumento de realização política". ${ }^{73}$

Por fim, resta clara a posição da autora acerca do tema da jurisdição constitucional, esperando-se do Judiciário ${ }^{74}$ uma ação de inclusão dos excluídos, concretizando a Constituição, ou realizando o sistema de direitos constitucionais para eliminar as perversas divisões sociais que caracterizam a sociedade brasileira ${ }^{75}$, posto que o objetivo principal do constitucionalismo brasileiro é o da implementação da justiça distributiva ${ }^{76}$, que, por sua vez, pode ser compatível com uma distribuição

${ }^{70}$ CITTADINO, G., op. cit., p. 19.

${ }^{71}$ Ibid., p. 63-64.

${ }^{72}$ Ibid., p. 62-63.

${ }^{73}$ Ibid., p. 65.

${ }^{74}$ É de se destacar que Cittadino não considera o controle difuso de constitucionalidade como uma verdadeira forma de jurisdição constitucional, uma vez que decide o caso concreto, não tendo, portanto, a função de guardião dos valores que integram o sentimento constitucional da comunidade. Cf. CITTADINO, G., op. cit., p. 65.

${ }^{75}$ Confira-se: "Parece não restar dúvida de que o constitucionalismo ‘comunitário' brasileiro, especialmente no que diz respeito ao tema da jurisdição constitucional, luta por um Poder Judiciário cujo papel fundamental seja o de ajustar o ideal 'comunitário' dos valores compartilhados à realidade constitucional. Esperam do Judiciário uma ação de inclusão dos excluídos, 'concretizando a Constituição', como advoga Canotilho, ou, nas palavras de José Afonso da Silva, 'realizando o sistema de direitos constitucionais', para eliminar as perversas divisões sociais que caracterizam a sociedade brasileira". CITTADINO, G., op. cit., p. 68.

${ }^{76}$ Ibid., p. 73. 
desigual dos bens sociais, já que "falar de justiça não significa falar de igualdade simples" "77, mas de igualdade complexa, que garante a diferença, porém impede a dominação e a subordinação ${ }^{78}$. Desta forma a justiça não se volta contra a diferença, e sim contra a submissão e a subordinação.

Por outro lado, ressalta a autora que a idéia de que todos os cidadãos são livres e iguais é partilhada por liberais, comunitários e crítico-deliberativos que, conseqüentemente, também defendem, para as democracias contemporâneas, "não apenas a existência de uma Constituição, como também a constitucionalização dos direitos fundamentais" $"$.

A grande diferença entre a concepção proposta por Cittadino e a proposta por Streck a respeito do constitucionalismo brasileiro reside no fato de que ela defende uma maior participação dos cidadãos no processo deliberativo - não aquele existente no fórum Legislativo, mas no fórum público de deliberação criado no âmbito do Poder Judiciário, defendendo um aumento da "comunidade de intérpretes" da Constituição. ${ }^{80}$

Neste sentido, as conclusões desta autora:

De qualquer forma, do ponto de vista jurídico, parece não haver outra forma de enfrentar as marcantes divisões sociais da sociedade brasileira, buscando superar a cidadania de baixa intensidade, senão conferindo prioridade aos mecanismos participativos que buscam garantir o sistema de direitos fundamentais assegura-

\footnotetext{
${ }^{77}$ Ibid., p. 125.

${ }^{78}$ Ibid., p. 121 et. seq.

${ }^{79}$ Ibid., p. 125.

${ }^{80} \mathrm{O}$ que já pode ser constatado na medida em que a Constituição adotou novos e diferentes institutos processuais que, por sua vez, passaram a assegurar a intérpretes informais a iniciativa da deflagração do controle de constitucionalidade.Veja-se: "Art. $5^{\circ}$. LXX - o mandado de segurança coletivo pode ser impetrado por: ...b) organização sindical, entidade de classe ou associação legalmente constituída em funcionamento há pelo menos um ano, em defesa dos interesses de seus membros ou associados; LXXI - conceder-se-á mandado de injunção sempre que a falta de norma regulamentadora torne inviável o exercício dos direitos e liberdades constitucionais e das prerrogativas inerentes à nacionalidade, à soberania e à cidadania;' LXXIII - qualquer cidadão é parte legítima para propor ação popular que vise a anular ato lesivo ao patrimônio público ou de entidade de que o Estado participe, à moralidade administrativa, ao meio ambiente e ao patrimônio histórico e cultural, ficando o autor, salvo comprovada má-fé, isento de custas judiciais e do ônus da sucumbência; Art. 74, § $2^{\circ}$ Qualquer cidadão, partido político, associação ou sindicato é parte legítima, para, na forma da lei, denunciar irregularidades ou ilegalidades perante o Tribunal de Contas da União; Art. 103. Podem propor a ação de inconstitucionalidade: I - o Presidente da República; II - a Mesa do Senado Federal; III - a Mesa da Câmara dos Deputados; IV - a Mesa de Assembléia Legislativa; V - o Governador de Estado; VIo Procurador-Geral da República; VII - o Conselho Federal da Ordem dos Advogados do Brasil; VIII - partido político com representação no Congresso Nacional; IX - confederação sindical ou entidade de classe de âmbito nacional".
} 
dos na Constituição Federal. Estão corretos, portanto, os constitucionalistas 'comunitários' ao conferir prioridade aos temas da igualdade e da dignidade humanas. A participação cidadã pode certamente buscar, através dos vários institutos previstos no texto constitucional, a efetivação das normas constitucionais protetoras dos direitos fundamentais. Nesta perspectiva, o sistema de direitos assegurados pela Constituição Federal apenas terá efetividade mediante a força da vontade concorrente dos nossos cidadãos em processos políticos deliberativos. Esta cidadania juridicamente participativa, entretanto, dependerá, necessariamente, da atuação do Poder Judiciário - especialmente da jurisdição constitucional -, mas sobretudo do nível de pressão e mobilização política que, sobre ele, se fizer. ${ }^{81}$

Deste modo conclui ela que, nas sociedades contemporâneas, a jurisdição constitucional, seja nos países de civil law ou de common law, "tem atuado intensamente como mecanismo de defesa da Constituição e de concretização das suas normas asseguradoras de direitos" ${ }^{\prime 2}$, e que se nos países de common law esta prática criativa já é habitual, mesmo nos países de sistema continental, com os novos textos constitucionais incorporando princípios e configurando Estados Democráticos de Direito, acaba-se por deixar um espaço necessário para interpretações construtivistas por parte da jurisdição constitucional, "já sendo possível falar em um 'direito judicial' em contraposição a um 'direito legal'”83.

Cláudio Ari Mello define a posição adotada por Cittadino como republicanismo substantivo, tendo em vista que "embora permaneça centrado na participação política dos cidadãos de uma comunidade organizada em torno de um conjunto de valores éticos, também reconhece na constituição a ordem concreta expressiva desses valores" ${ }^{\prime 4}$, representando um meio-termo entre as teorias constitucionais democráticas e as teorias substantivas da Constituição.

Diversamente da posição adotada pelos autores acima, cabe ainda considerar a sustentada por Luiz Fernando Barzotto, no sentido de que a Constituição Federal de 1988 adota uma concepção procedimental de democracia, entendendo que "a democracia constitucional brasileira é, assim, uma democracia deliberativa na medida em que somente um regime baseado na deliberação, na razão prática, está em conformidade com a concepção do povo como comunidade de pessoas humanas" tal como previsto na Constituição de 1988.

\footnotetext{
${ }^{81}$ CITTADINO, G., op. cit., p. 231-232.

${ }^{82}$ Ibid., p. 233.

${ }^{83}$ Ibid., p. 232.

${ }^{84}$ MELLO, C. A, op. cit., p. 83.

${ }^{85}$ BARZOTTO, Luis Fernando. A democracia na Constituição. São Leopoldo: Unisinos, 2003, p. 181 .
} 
Em sua teoria, Barzotto defende que a Constituição brasileira de 1988 não é neutra, pois já no Preâmbulo possui um rol de valores a ser protegidos, assim como em todo texto da Constituição, tais como liberdade, segurança, bem-estar, desenvolvimento, igualdade, justiça, solidariedade, justiça social, função social da propriedade etc. Entretanto, "como ninguém pode saber a priori o que significa liberdade, segurança, desenvolvimento, nas várias situações concretas" $"$, faz-se necessária a discussão desses valores por meio da democracia deliberativa, "que é o regime em que o conteúdo dos valores são determinados pelo povo em deliberação conjunta". ${ }^{87}$

Dessa forma, apesar de afirmar que "a Constituição de 1988 consagra uma série de valores, direitos e princípios que formam a ordem concreta de convivência dos brasileiros"88, a sua interpretação e sua aplicação devem ser feitas pelo viés da democracia deliberativa, ou seja, é o povo quem vai dar a dimensão dos valores expressos na Carta Constitucional, priorizando assim o processo democrático.

Barzotto não aprofunda o estudo a respeito do papel da jurisdição constitucional no contexto da Constituição de 1988. Não obstante, entende que a atividade judicial "deve ser compreendida como uma continuação do processo deliberativo democrático que se dá no âmbito da representação popular", ou seja,

(...) o juiz não pode pensar sua atividade como uma mera adesão a normas positivadas (normativismo) nem pode criar o direito ex nihilo (decisionismo), mas está obrigado a dar continuidade, em cada caso, à discussão democrática que se expressa nas leis e decretos dos poderes legitimados pelo voto popular. ${ }^{89}$

Assim, muito embora sustente a participação popular para determinação dos valores fundamentais constitucionais, entende que este processo de deliberação e discussão dos cidadãos encontra limites na teleologia constitucional, razão por que também deve o processo judicial conceber-se "como uma atividade de concretização das finalidades da constituição e das leis em conformidade com esta". ${ }^{90}$

Pode-se verificar, dessa maneira, que, mesmo propugnando por um processo judicial que seja uma continuação da discussão democrática expressa nas leis e decretos dos poderes legitimados pelo voto popular, Barzotto admite limites a essa

\footnotetext{
${ }^{86}$ Ibid., p. 191.

${ }^{87}$ Ibid., ibidem, p. 191.

${ }^{88}$ Ibid., p. 192.

${ }^{89}$ Ibid., ibidem.

${ }^{90}$ Ibid., p. 193.
} 
expressão da vontade popular com base na Constituição, e nos bens e valores nela expressos. Isto, em última análise, acaba por permitir um julgamento substantivo por parte do Poder Judiciário, levando à insustentabilidade de uma teoria puramente procedimental para a Constituição brasileira ${ }^{91}$. Outro aspecto a ser ressaltado é o de que a democracia procedimental defendida pelo autor se dá a posteriori e nos limites dos bens e valores protegidos pela Constituição, questionando sobre "quem fiscaliza o respeito pelas restrições à democracia e quais são os limites da autoridade fiscalizadora" 92 .

Nesse sentido a posição de Cláudio Ari Mello:

Barzotto não se detém na função da justiça constitucional no arranjo institucional da democracia deliberativa. É certo que o acento deliberativo da sua concepção republicana privilegia os processos democráticos no reconhecimento e na definição dos conteúdos constitucionais. Como ele assinala reiteradamente, o significado concreto da vida boa e do bem comum deve ser atingido pelo uso da razão prática em processos dialógicos abertos a todos os membros da comunidade, porque somente o debate racional ente múltiplos pontos de vista pode produzir um significado conforme o telos da comunidade.

Entretanto, como os direitos fundamentais, os princípios e os valores constitucionais fornecem pautas parcialmente determinadas quanto a esse telos, de modo que decisões democráticas podem ser classificadas como corretas ou incorretas, conforme sejam ou não compatíveis com aquelas pautas, não é de modo algum infundada a pergunta sobre o papel da justiça constitucional como guardiã dos fins constitucionalmente definidos. ${ }^{93}$

Concluindo-se, é possível afirmar que a Constituição brasileira é uma constituição de valores, escolhidos pela sociedade no momento constituinte e elevados à categoria de direitos fundamentais na Carta de 1988.

Assim, apesar da aparente tensão existente entre jurisdição constitucional e democracia, pode-se afirmar que mesmo Barzotto, ao defender uma concepção procedimental de democracia para o direito brasileiro, aceita a proteção dos direitos fundamentais como garantia do próprio processo democrático, na medida em que sem sua realização não haverá satisfação dos direitos individuais de liberdade de

\footnotetext{
${ }^{91}$ Veja-se a crítica de Cláudio Ari Mello: "Sem embargo, a teoria da democracia constitucional desenvolvida por Barzotto demonstra a dificuldade de conferir coerência lógica a qualquer concepção de democracia deliberativa que tente acomodar o princípio democrático como eixo da vida política, com fins ou valores pré-constituídos e que restringem o espaço de decisão dos processos democráticos". MELLO, C. A., op. cit., p. 83.

${ }^{92}$ Ibid., ibidem.

${ }^{93}$ Ibid., p. 82.
} 
expressão e de igual liberdade de participação política, necessários à existência de um processo democrático de discussão e deliberação. ${ }^{94}$

Além disso deve-se afastar a idéia de que a democracia esteja ligada apenas ao princípio majoritário; ela se liga igualmente à promoção da liberdade-igual, de proteção de minorias e de grupos vulneráveis que ficam fora do processo político democrático, por meio de uma hermenêutica constitucional comprometida com a efetivação dos direitos fundamentais individuais e sociais.

Ora, o Judiciário brasileiro, desse modo, exerce papel importante na proteção da democracia, vez que é ele o fórum adequado para garantia dos direitos das minorias, minorias essas que se tornam maioria numa sociedade plural e desigual como a brasileira. Ressalta-se que, sem a efetivação dos direitos sociais, os excluídos e as minorias nunca alcançarão uma igualdade real, ou uma liberdade igual, e, portanto, continuarão alheios ao processo democrático, pois não basta a garantia dos direitos políticos e de liberdade de expressão, é preciso também a garantia do direito à educação, para que se tenha o direito a formar a própria opinião.

Independentemente de qual nome se dá às teorias sustentadas por Cittadino, Streck ou Barzotto, é certo que todas convergem ao ponto de que o constitucionalismo brasileiro é substantivo, uma vez que adota valores consagrados pela sociedade no momento constituinte e que funcionam como limites aos próprios cidadãos, bem como aos atos dos Poderes públicos. Para além disso, todos concordam com a participação do Judiciário - enquanto intérprete maior da Constituição - na efetivação dos direitos fundamentais enquanto representação dos valores escolhidos pela sociedade $^{95}$, priorizando desta maneira a proteção dos direitos fundamentais como valor supremo do Estado Democrático de Direito instituído pela Constituição Federal de 1988.

\section{Referências}

AMARAL, Gustavo. Direito, escassez \& escolha: em busca de critérios jurídicos para lidar com a escassez de recursos e as decisões trágicas. Rio de Janeiro: Renovar, 2001.

BARBOZA, Estefânia Maria de Queiroz. A legitimidade democrática da jurisdição constitucional na efetivação dos direitos fundamentais sociais. Dissertação de Mestrado, PUCPR, Curitiba, 2005.

\footnotetext{
${ }^{94}$ NINO, C.S., op.cit., p. 222.

${ }^{95}$ Contrário a este posicionamento, ver BARZOTTO, L. F, op.cit., no $1^{\circ}$ Capítulo, no qual sustenta que a concepção de democracia assumida pela Constituição Federal de 1988 é a deliberativa.
} 
BARROSO, Luís Roberto. O direito constitucional e a efetividade de suas normas: limites e possibilidades da Constituição brasileira. 7. ed. Rio de Janeiro: Renovar, 2003.

BARZOTTO, Luis Fernando. A democracia na Constituição. São Leopoldo: Unisinos, 2003.

CANOTILHO, José Joaquim Gomes. Direito constitucional e teoria da Constituição. 3. ed. Coimbra: Almedina, 2000.

CAPPELLETTI, Mauro. O controle judicial de constitucionalidade das leis no direito comparado. 2. ed. Porto Alegre: Sérgio Antonio Fabris, 1999.

CITTADINO, Gisele. Pluralismo, direito e justiça distributiva: elementos da filosofia constitucional contemporânea. 3. ed. Rio de Janeiro: Lúmen Júris, 2004.

DWORKIN, Ronald. Freedom's law: the moral reading of the American Constitution. Second Printing. Cambridge: Harvard University Press, 1996.

Fontes, 2002.

Levando os direitos a sério. Trad. Nelson Boeira. São Paulo: Martins

. Los Derechos en serio. Trad. espanõla Marta Guastavino. 5.

reimpresión. Barcelona: Ariel. 2002.

. Uma questão de princípio. São Paulo: Martins Fontes, 2000.

ELY, John Hart. Democracy and distrust. 14. printing. Cambridge: Harvard University Press, 2002.

ERIKSEN, Erik Oddvar. Democratic or jurist made law? On the claim to correctness. ARENA- Centre for European Studies, University of Oslo, Working Papers WP 04/07, 2004. Disponível em: <www.arena.uio.no/publications/workingpapers2004/papers/wp04_7.pdf $>$. Acesso em 1 jul. 2005.

FAVOREU, Louis. As cortes constitucionais. Trad. Dunia Marinho Silva. São Paulo: Landy, 2004.

HÄBERLE, Peter. Hermenêutica constitucional. A sociedade aberta dos intérpretes da Constituição: contribuição para a interpretação pluralista e "procedimental" da Constituição. Trad. Gilmar Ferreira Mendes. Porto Alegre: Sérgio Antonio Fabris, 2002.

HABERMAS, Jürgen. Direito e democracia: entre facticidade e validade. 2 v., 2. ed. Trad. Flávio Beno Siebeneichler. Rio de Janeiro: Tempo Brasileiro, 2003.

KOZICKI, Katya. Conflito e estabilização: comprometendo radicalmente a aplicação do direito com a democracia nas sociedades contemporâneas. Tese de Doutorado, Universidade Federal de Santa Catarina, Florianópolis, 2000.

MELLO, Cláudio Ari. Democracia constitucional e direitos fundamentais. Porto Alegre: Livraria do Advogado, 2004.

Revista Seqüência, no 56, p. 151-176 jun. 2008. 
NINO, Carlos Santiago. The Constitution of deliberative democracy. New Haven: Yale University Press, 1996.

OLIVEIRA, Marcelo Andrade Cattoni de. Jurisdição constitucional: poder constituinte permanente? In: SAMPAIO, José Adércio Leite; CRUZ, Álvaro Ricardo de Souza. Hermenêutica e jurisdição constitucional. Belo Horizonte: Del Rey, 2001.

SILVA, José Afonso da. Curso de direito constitucional positivo. 13. ed., São Paulo: Malheiros, 1997.

SOUZA NETO, Cláudio Pereira de. Jurisdição constitucional, democracia e racionalidade prática. Rio de Janeiro: Renovar, 2002.

STRECK, Lenio Luiz. Jurisdição constitucional e hermenêutica: uma nova crítica do direito. 2. ed. Rio de Janeiro: Forense, 2004. 